\title{
Storyboarding Pervasive Learning Games
}

\author{
Klaus P. Jantke ${ }^{1} \&$ Sebastian Spundflasch $^{2}$ \\ ${ }^{1}$ Fraunhofer IDMT, Children's Media Department, Erfurt, Germany \\ ${ }^{2}$ Ilmenau University of Technology, Institute of Media Technology, Ilmenau, Germany
}

\begin{abstract}
Game-Based Learning (GBL, for short) is apparently very attractive and challenging field of technology enhanced learning. In game-based learning, the technological systems employed for the purpose of learning are digital games. Stand-alone serious games are rare. Games employed for learning need to be embedded into suitable contexts. An approach promising from certain didactic perspectives and driven by a variety of characteristics of learning contents and training requirements is embedding those games into the surrounding physical world. Games embedded into the physical world are called pervasive games. The ways of embedding are paramount. There have been numerous attempts to design and to implement pervasive games, in general, and to employ pervasive games for learning purposes, in particular. Pervasive games bear the enormous potential of more affective and effective learning experiences due to the many opportunities of interacting with other players and with the real world. Storyboarding the interaction between the real world and the virtual world of a pervasive game reveals the essential strengths and weaknesses of the game concept and allows for diagnosing didactic flaws of game play. Furthermore, the approach supports the design of more effective pervasive games.
\end{abstract}

Keywords: Game-Based Learning, Serious Games, Pervasive Games, Storyboarding.

\section{Pervasive Games for Learning}

Game based learning is apparently an established paradigm within technology enhanced learning (see, for instance, [15]), although it does not yet play any remarkable role in e-learning conference series.

The authors' present contribution is a small attempt to overcome this apparent deficiency.

Contemporary taxonomies and classifications of serious games such as [16] and [18] do not even mention the term pervasive game or the game property of being pervasive.

This particularly unsatisfactory state of the art bears abundant evidence of the need for pondering the peculiarities of those serious games that fall into the category of pervasive games as well.

No doubt, there are serious games which are not pervasive and there are pervasive games which do not deserve to be called serious. This paper's focus is on the intersection of the two categories, exclusively.

A game may be called pervasive if the experience of playing is based on a certain mixing of real world elements and virtual elements. Crucial to the human experience is the interplay between the real world and the virtual layer [7] which, by the way, is crucial to understand some game's impact, in general, and the way in which the game works for teaching and learning, in particular. Virtual actions may be the trigger for physical actions in the real world and vice versa.

Playing whatever pervasive game is characterized by face-to-face communica- 
tion and social interactions among players, physical interactions between human players, physical activities in real environments, the dynamics of reality influencing game play, virtual world components expanding reality, as may also be seen in publications such as the survey book [13].

The virtual game world may give new meanings to parts of the real world. For instance, some road may be seen as a river and some building becomes a castle. Beyond the limitations of conventional digital games, actions in the game world may have real-world preconditions and may require real-world actions.

According to constructivist approaches to learning [19], human learners acquire knowledge in an active process which may be highly iterative. In dependence on the general domain and the specific subject of learning, experimentation, trial and error, haptic experience and the like may be crucial. In game-based learning, pervasive games are those bridging the gap to real experiences in the real world.

Even rather simple approaches to playing pervasive games for purposes of learning-compared to conventional classroom approaches-may lead to some higher energetic activation, more positive emotions and attitudes towards learning activities [8]. In some sense, pervasive games bear to opportunity of exercising in the real world, in many cases an issue of health and prevention.

In many areas of learning, pervasive games provide authentic experiences. When you learn about the history of a city or about the trees in the forest, it is surely preferable to do so in the city and in the forest, respectively.

Humans learn best through affective experiences. Storyboarding is the technology of anticipating and designing forthcoming human experience.

\section{Storyboarding as a Methodology of Educational Media Design}

The present paper uses storyboarding as a technology, but does not aim at anything such as an introductory course to storyboarding. The authors rely on the basics as introduced by [5] and confine themselves to those notions and notations needed for the purpose of characterizing pervasive games. Recent work on storyboarding digital games such as [6] and [9], e.g., is worth some comparison.

Storyboards are hierarchically structured graphs. The composite nodes are named episodes, whereas the atomic nodes are named scenes. Composite nodes may be subject to substitution by other graphs. In contrast, atomic nodes have some semantics in the underlying domain. They may represent documents such as videos, pictures, or text files in formats like pdf, e.g., but they may also represent some activities of human learners, co-learners, teacher, tutors, or those actions performed by a digital systems. The usage of composite nodes in some storyboard graph allow for a remarkably declarative representation of anticipated experiences on different levels of granularity-cf. the idea of layered languages of ludology [9].

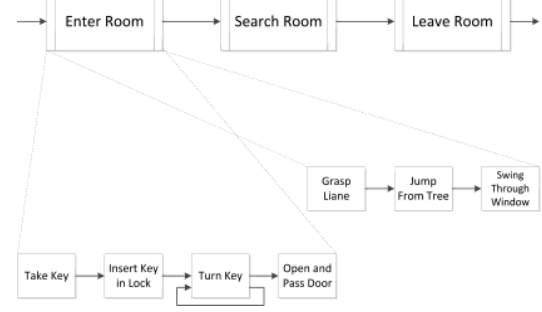

Fig. 1: Cutout of a Storyboard with 3 Episodes

For illustration, the storyboard in the figure above shows alternative substitutions for some episode. In general, storyboards contain parallelisms and alternatives and, as shown, branches and loops. 


\section{Storyboarding Pervasive Games Characteristics Key to Learning}

This section is aiming at the representation of three different pervasive games to demonstrate the way in which characteristics show in the storyboard which are crucial to learning

\subsection{Treasure}

The game selected for an introduction by example is TREASURE [3] which is one of the earliest pervasive games with some clear educational intention behind. Its authors call TREASURE an outdoor mobile game. The core idea underlying the game is easy in structure.

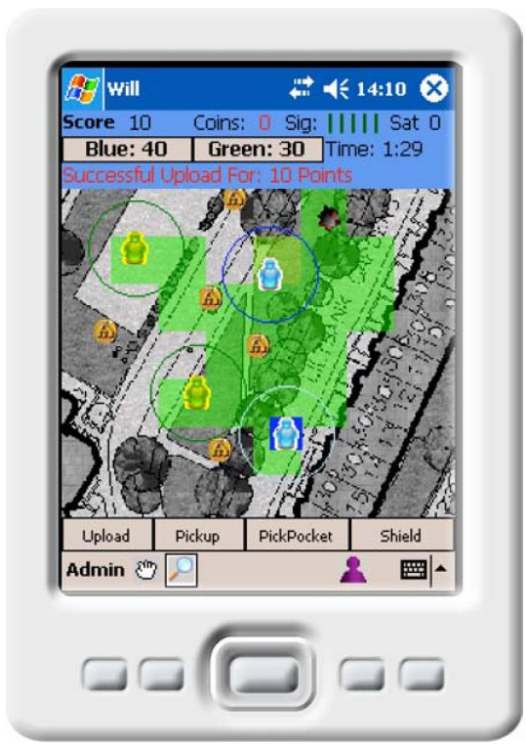

Fig. 2: Touch \& Feel of the TREASURE Game

Some real urban environment such as a park, e.g., is virtually equipped with some virtual treasures. Teams of players are running around in pursuit of treasures. Team members in the real world are localized by means of GPS technology relating them to the virtual treasures and to each other (see storyboard in figure 3). In particular urban places, there are WLAN connections allowing players to contact their virtual treasure boxes on the game server for upload.

Chalmers et al. [3] describe variations of the game mechanics. The core idea, however, is lucidly summarized by some simple storyboard as shown in figure 3 below.

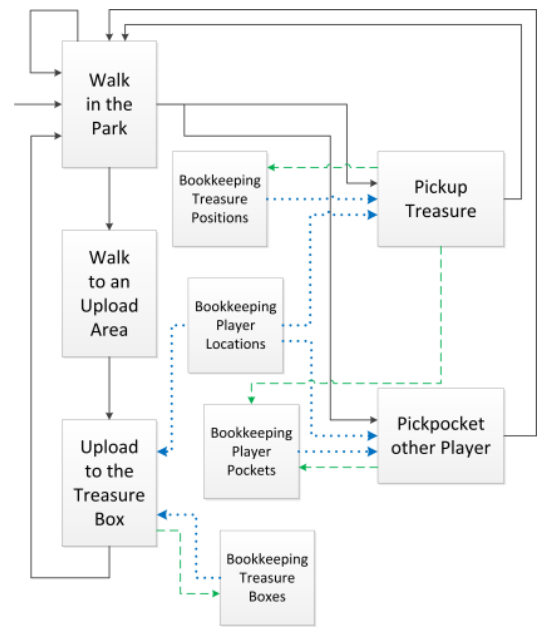

Fig. 3: The TrEasure Top Level Storyboard

Every node is an episode or a scene describing some action. Smaller inscriptions describe actions of the computer system as opposed to actions of human players. Solid lines indicate the passing of a human player from one action to another such as, for illustration, from just walking to picking up some treasure. Dashed green lines indicate that the player's action causes some actions of the computer system. In turn, dotted blue lines indicate the impact of earlier game actions on the player's current actions. For instance, virtual treasures can only be discovered and picked up where the computer system has placed them virtually. Arrows indicating update operations of the players' positions have been dropped.

Game playing means moving around, collecting virtual treasures, trying to pickpocket each other, and aiming at uploads of the own virtual treasure to the 
safe virtual treasure box. Bookkeeping of treasure locations and treasure boxes defines the termination of game play.

The simplicity of the storyboard above reflects the simple structure of the underlying game concept.

Furthermore, it exhibits that there are no actions of interest performed by the game system except bookkeeping and, thus, determining preconditions of player actions. The game system is not perceived as an actor, but more seen as a supervising game master.

The TREASURE game addresses issues of learning about wireless communication technologies, especially about seamful communication. For mastery of the game, some mastery of the varying options of communication is required.

The dotted and the dashed lines of the storyboard on display in figure 3 above indicate the in-game communication key to learning.

\subsection{REXPLORER}

REXPLORER is the name of some pervasive game developed for playfully learning about the history of the German city of Regensburg.

In this game, the player is guided by GPS to certain points in the city. At these points, historical knowledge is imparted to the player through story-driven multimedia learning content. At each station, players can answer questions in a quiz to score and to get a certain reward-coveted "Magic".

As can be detected from some top level storyboard of the REXPLORER game (see fig. 4), this particular game is even simpler in structure than TREASURE. REXPLORER's virtual game world does not substantially contribute to an original game playing experience. The communication between and the connection of the real and the virtual game world represented by green dashed arrows and blue dotted arrows in fig. 4 is rather poor.
Furthermore, a comparison of the two storyboards reveals a certain similarity of the game mechanics.

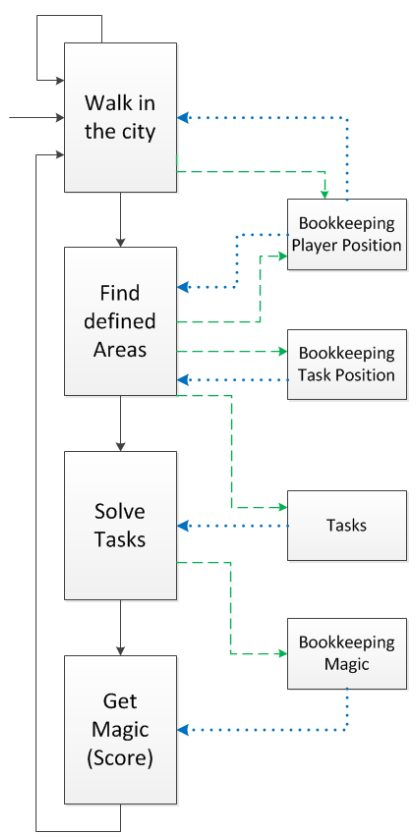

Fig. 4: REXPLORER Top Level Storyboard

The present section will be completed by another pervasive game study below.

\subsection{INVISIBLE BUILDINGS}

INVISIBLE BUILDINGS is some pervasive game explicitly aiming at learning events in school [20,21].

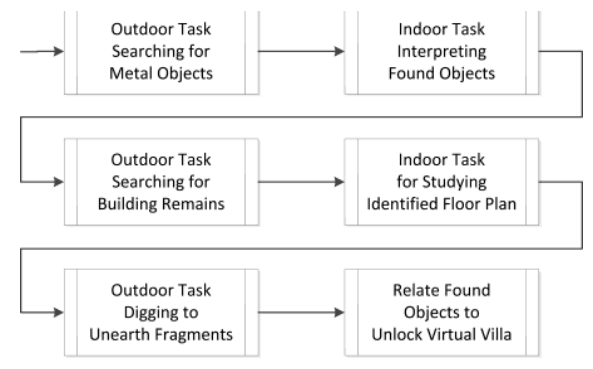

Fig. 5: INVISIBLE BuILDINGS Top Level Storyboard Relating Outdoor and Indoor Activities

Playing this game requires enormous efforts and is rather expensive. 
Unfortunately, papers such as [20] and [21] do not provide sufficient detail to reliably expand the storyboard shown in figure 5. Therefore, the authors confine themselves to a rather rough approach as shown in figure 6.

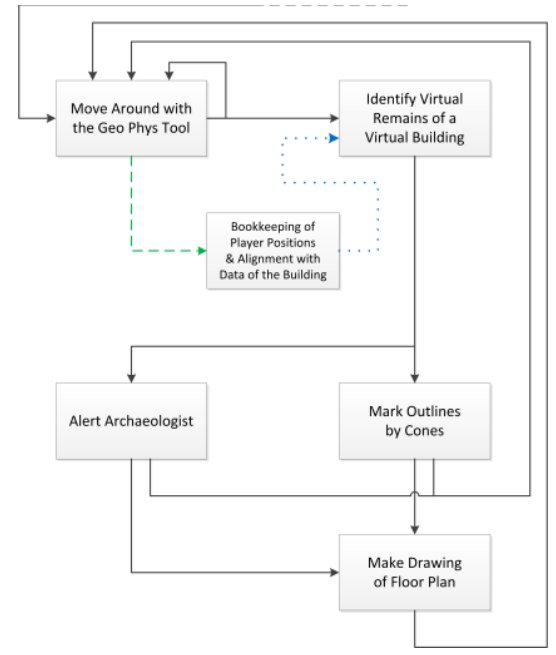

Fig. 6: INVISIBLE BuILDINGS Storyboard Expansion of one of the three Outdoor Episodes

The storyboard of fig. 6 shows in some more detail the outdoor episode of walking around with some Geo Phys tool.

Players are moving around and are watched, so to speak, by the game system. When they are coming close to some real position where some virtual building remains are virtually hidden, the Geo Phys tool responds. This crucial game playing activity is indicated by the dashed and dotted lines of the storyboard. Real outdoor activities are triggered such as alerting the archaeologist and marking the outlines of the virtual finding physically. The player's drawing of the floor plan is continued. There is a large variety of real player activities.

When this episode is completed, the real floor plan drawing which indicates the virtual building found is carried over to the next indoor episode. Learning takes places by reflexion of playing experience.

\section{Didactic Design of Pervasive Games for Education - Lessons Learned}

Seen from a certain bird-eyes view, storyboarding means the design of forthcoming experience, in general (see [5], [6], and [9]). Complex didactic processes can not be implemented from scratch. There is abundant evidence of the need for methodologies and tools supporting the systematic design of computer-supported educational processes. Storyboarding is key, because it provides some digital output - the storyboard itself-which can be used directly in the running system.

In particular, storyboards are the working documents based on which designers, artists, educational specialists and system developers may communicate.

Applied to pervasive games, several peculiarities make storyboarding even more useful.

First, storyboarding allows for some visually appealing and intuitive understanding of the separation of the virtual game world from the real game world. This enables the designer to work on both worlds separately. Second, storyboarding allows for particular emphasis on the communication between the two worlds. Third, storyboarding allows for a wellfounded comparison of pervasive games based on some comparison of their storyboards-a firm basis for classification.

\section{Acknowledgement}

This work is based on the second author's diploma thesis entitled "Analyse von Pervasive Games und theoriegeleitete Entwicklung eines technologisch getriebenen Konzeptes für ein Spiel im urbanen Raum", Ilmenau University of Technology, Germany, 2011. Furthermore, the work relates to the first author's current engagement in several pervasive games projects for purposes such as training staff for disaster management. 
Colleagues and friends who have been working on storyboarding particular educational projects, in general, and serious games, in particular, have been very helpful partners. The authors want to thank Rainer Knauf, Anja Hawlitschek (with her adventure game “1961”), Jacqueline Krebs, Christian Kirchner, and Antonio Purrmann (with the game "Catch 22"), Jun Fujima and Sebastian Arnold (with the game "TraSt").

\section{References}

[1] R. Ballagas and S. Walz, "REXplorer: Using player-centered iterative design techniques for pervasive game development," Pervasive Game Applications - A Reader for Pervasive Gaming Research, C. Magerkurth and C. Röcker (eds.), pp. 255-284, Shaker Verlag 2007.

[2] J. Borchers, "Pervasive game", Forschung und Lehre, p. 31, 1:2007.

[3] M. Chalmers, M. Bell, B. Brown, M. Hall, S. Sherwood, and P. Tennent, "Gaming on the edge: Using seams in ubicomp games", Proc. 2005 ACM SIGCHI International Conference on Advances in Computer Entertainment Technology ACE'05, pp. 306-309, New York, NY, USA, 2005.

[4] K. P. Jantke, "Pattern concepts for digital games research", Knowledge Media Technologies, First International Core-to-Core Workshop, G. Kreuzberger and K. P. Jantke (eds.), TU Ilmenau, IfMK, Diskussionsbeiträge 21, pp. 29-40, 2006.

[5] K. P. Jantke and R. Knauf, "Didactic design through storyboarding: Standard concepts for standard tools", Proc. $4^{\text {th }}$ International Symposium on Information and Communication Technologies, Cape Town, South Africa, 2005, B.R.
Baltes, L. Edwards, F. Galindo et al. (eds.), pp. 20-25, Dublin, Ireland: Computer Science Press, 2005.

[6] K. P. Jantke and R. Knauf, "Taxonomic concepts for storyboarding digital games for learning in context", $4^{\text {th }}$ International Conference on Computer-Supported Education, CSEDU 2012, Porto, Portugal, M. Helfert, M.J. Martins, and J. Cordeiro (eds.), pp. 401-409, SciTePress, 2012.

[7] K. P. Jantke and D. Lengyel, "Die Realität in virtuellen Welten“, Zeitschrift für e-Learning 7(1): 7-22, 2012.

[8] C. Kittl, F. Edegger, and C. Petrovic, "Learning by pervasive gaming: An empirical study", Innovative Mobile Learning, New York, NY, USA, 2009.

[9] R. Knauf, Y. Sakurai, S. Tsuruta, and K. P. Jantke, "Modeling didactic knowledge by storyboarding", $J$. Educational Computing Research 42(4): 355-383, 2010.

[10] C. Lenerz, "Layered Languages of Ludology - eine Fallstudie", Digitale Spiele

Herausforderungen und Chance, A. Beyer und G. Kreuzberger (Hg.), Boizenburg, Germany: VWH, pp. 39-52, 2009.

[11] I. Lindt, L. Ohlenburg, U. PankokeBabatz, and S. Ghellal, "A report on the crossmedia game Epidemic Menace", ACM Computers in Entertainment 5(1): 1-8, 2007.

[12] F. Markovic, O. Petrovic, C. Kittl, and B. Edegger, "Pervasive learning games: A comparative study", New Review of Hypermedia and Multimedia, 13(2): 93-116, 2007.

[13] M. Montola, J. Stenros, and A. Waern (eds.), "Pervasive Games: Theory and Design", Elsevier/Morgan Kaufmann, 2009. 
[14] J. Peitz, H. Saarenpää, and S. Björk, "Insectopia: Exploring pervasive games through technology already pervasively available", Proc. 2005 ACM SIGCHI International Conference on Advances in Computer Entertainment Technology ACE'05, pp.107-114, New York, NY, USA, 2005.

[15] M. Prensky, "Digital Game-Based Learning", McGraw-Hill, 2001.

[16] R. Ratan and U. Ritterfeld, "Classifying serious games", Serious Games. Mechanisms and Effects, U. Ritterfeld, M. Cody, and P. Vorderer (eds.), pp. 10-24, New York, NY, USA: Routledge, 2009.

[17] U. Ritterfeld, M. Cody, P. Vorderer, "Serious Games. Mechanisms and Effects", New York, NY, USA: Routledge, 2009.

[18] B. Sawyer and P. Smith, Serious games taxonomy, http://www.seriousgames.org/presen tations/serious-games-taxonomy- 2008_web.pdf, 2008 [last access: Dec. 12, 2009].

[19] F. Thissen, "Das Lernen neu erfinden? Konstruktivistische Grundlagen einer Multimedia.Didaktik“, Europäischer Kongress für Bildungstechnologie und betriebliche Bildung, U. Beck und W. Sommer (Hg.), pp. 69-79, Karlsruhe, Germany, 1997.

[20] M. Winter and L. Pemberton, "Unearthing invisible buildings: Device focus and device sharing in a collaborative mobile learning activity", International Conference on Mobile Learning, Malta, Oct. 19-22, 2010.

[21] M. Winter and L. Pemberton, "Unearthing invisible buildings: Device focus and device sharing in a collaborative mobile learning activity", Innovations in Mobile Educational Technologies and Applications, D. Parsons (ed.), pp. 77-95, Hershey, PA, USA: Information Science Reference, 2012. 